\title{
Espacios públicos y construcción de ciudad
}

\section{Public spaces and city construction}

\author{
Antonio García García* y Francisco José Torres Gutiérrez*
}

Hábitat y Sociedad (ISSN 2173-125X), n. ${ }^{\circ}$ 9, noviembre de 2016, pp. 5-8.

* Departamento de Geografía, Historia y Filosofía. Universidad Pablo de Olavide.
$\mathrm{P}$ ártase de que la vigencia del binomio ciudad-espacio público cobra sentido toda vez que este se considere un hecho urbano en su complejidad y no meramente un hecho urbanístico. De no ser así no tendría cabida el debate en torno a la necesidad de espacios públicos atractivos -en términos de ubicación, confort, reconocimiento o uso- o de su dimensión como sistema interescalar y diverso -en términos de complementariedad o equilibrio-. Es precisamente el reconocimiento de esta complejidad del espacio público el que implica aproximaciones reflexivas sobre fórmulas de gestión de la ciudad a una escala que permita atender a los caracteres y dinámicas de cada barrio-zona, y/o en la incorporación activa de la comunidad tanto en el día a día del espacio público - práctica del espacio desde la que desarrollar sentimientos de pertenencia ya apego- como en su propia construcción.

A lo largo de la historia los espacios públicos han sido reflejo y depositarios de los distintos intereses y actores de ese microuniverso - a veces sorprendente, otras decepcionante- que llamamos ciudad. Están construidos, dotados, vividos u obviados en base a ellos y son relato no solo de formas de imaginar sino de pertenecer a la misma. Así la sentencia un espacio público para ver y dejarse ver adquiere distintos significados en el tiempo, en el espacio y en sus protagonistas. En cualquier caso no hay un único espacio público, sino muchos; tantos como tipologías de lugares, como contextos socio-urbanísticos o como formas de hacer - o no- ciudad y ciudadanía. De este modo, en nuestros hábitats urbanos coexisten vacíos, espacios inadecuadamente atendidos o lugares con tratamientos epidérmicos y banales, con buenas prácticas, espacios reconocidos y vitales, experiencias de recuperación y reciclaje o iniciativas modestas cuyo éxito reside en su propuesta y realización desde el propio vecindario.

Por todo ello se considera irrenunciable, en el marco de una publicación como esta, el acercamiento al debate sobre los espacios públicos desde una postura abierta al aprendizaje resultante de reflexiones y experiencias diversas, acorde a la multiplicidad de funciones, facetas y fórmulas de aproximación a los espacios públicos. En consecuencia, el número 9 de Hábitat y Sociedad nace como un número ecléctico que evidencia que el relato sobre los mismos es tan actual como dinámico y cambiante. En algunos de los textos aparecen como hechos protagonistas de los análisis efectuados, en otros manifiestan su importancia ante procesos o intervenciones donde se presta especial atención a fenómenos sociales, políticos o en general urbanísticos. 
"Si planificas para gente y lugares... consigues más gente y lugares." Este principio, tomado del movimiento Project for Public Spaces, bien puede ser uno de los ejes fundamentales del primer bloque de contribuciones al número, en cuya disparidad de acercamientos es posible identificar el común interés por pensar, proyectar y/o gestionar espacios públicos desde su vocación de lugares para la ciudadanía frente a la materialización de la distopía de espacios ajenos a la ciudad, sea por tratarse de espacios olvidados, desatendidos o bellos pero inertes. Ahora bien, los dos primeros artículos recorren el camino desde disímiles puntos de partida.

El texto de Claudia María Sacristán Pérez, Centopiazze. La ciudad periférica a través del vacío, trata una experiencia de intervención de arriba abajo concreta, en el caso de Roma, cuyo interés se colige de su visión coordinada y hasta cierto punto permeable a distintos agentes. En su marco surgen proyectos puntuales en principio destinados a la consecución de lugares reconocibles y vitales, muchos de ellos en la periferia, siendo útil valorar su resultado en base a lecturas que, junto a la fisonomía de las plazas, atiendan a sus dinámicas de uso en entornos urbanos y sociales específicos.

El carácter diferencial que supone la intervención en centros y periferias, y la réplica a la planificación convencional en favor de los procesos de construcción colectiva, quedan plasmados, desde otra perspectiva, en el texto de Adrián Hernández Cordero, El Forat de la Vergonya: entre la ciudad planificada y la ciudad habitada. De nuevo, a través de un ejemplo concreto, en este caso una céntrica plaza de Barcelona, se ponen de manifiesto escenarios de conflicto más amplios: entre renovación y reciclaje urbanos; entre intereses y actores en tramas centrales; entre ciudad y mercado.

La lectura del barrio, como ámbito desfavorecido social y habitacionalmente que demanda su transformación, y de la participación como dimensión genérica de la esfera pública, queda definitivamente patente en el artículo de Cristina Gallego Gamazo, Análisis de la implicación de la diversidad de actores en el Plan Integral del Polígono Sur: una mirada sistémica e integrada. El artículo destaca, con una visión crítica sustentada en los resultados de entrevistas a diversos actores, la necesidad de intervenir en un barrio como Polígono Sur, en Sevilla, en función de criterios de integralidad, participación y adaptación al territorio. En el seno de este enfoque y objetivo general del texto, aparecen reflejados los valores que pueden presentar algunos espacios públicos concretos al funcionar como lugares de interacción y sociabilidad.

Por su parte, un segundo bloque de contribuciones ponen de manifiesto que el poliedro que son los espacios públicos no solo tiene que ver con sus distintas formas de plasmación y dinámicas de uso o apropiación, sino que otorga un significado complementario a un mayor elenco iniciativas transformadoras de la ciudad actual. Cabría citar, entre otras, movimientos sociales, nuevas fórmulas colaborativas y/o económicas, movilidad, arte público, educación...

De acuerdo con Laura Pérez Prieto y Mónica Domínguez Serrano, autoras del texto Movimientos sociales sevillanos: ¿preocup-acciones ecologistas y feministas para construir otro modelo de ciudad?, la sociedad civil está jugando un papel fundamental a la hora de hacer política urbana y de abrir el estrecho debate sobre la sostenibilidad, para incluir en él no solo cuestiones ecológicas, sino también de justicia social e igualdad de género. Entre las iniciativas consideradas en el caso de Sevilla —formuladas como "praxis urbanas: apuestas por el cuidado de la vida 
en la ciudad" - apuntamos como ejemplos las que se catalogan como "iniciativas por la defensa del territorio" y que afectan a determinados parques y huertos sociales en la ciudad. Las luchas ciudadanas por estos espacios son plantean como experiencias de cohesión y transformación social.

La contribución de Esteban de Manuel Jerez, Conso González Arriero y Marta Donadei, titulada Las redes de Movilidad Urbana Sostenible y la reactivación del Espacio Público: Alcosa, está fundamentada en el desarrollo de un proyecto de Investigación Acción Participativa (I.A.P.) enmarcada bajo el concepto de "Barrios en Transición". En ella se ofrece un diagnóstico - aplicado sobre el barrio sevillano de Parque Alcosaen el que se evalúa la relación entre el modelo de movilidad y la ocupación del espacio público. El interesante proceso participativo llevado a cabo con/entre el vecindario permite generar una propuesta de intervención que se traduce también en una serie de planos. Además de limitarse la ocupación del espacio público que se produce por los vehículos privados, la propuesta incide en la eficiencia de la red de transporte público y en la red y dotaciones necesarias para un mayor uso de la bicicleta.

El artículo PaisajeSur, autoconstruyendo Usera-Villaverde. Paisaje y Arte, estrategias de la acción social en el espacio urbano, de China C. Cabrerizo, es un claro reflejo de nuevos modos de ver los procesos de construcción de la ciudad a partir de espacios públicos incluyendo argumentos no siempre convencionales - menos aún en la periferia urbana-como el arte público, el paisaje o el patrimonio entendido como proceso. Esto en el contexto de una iniciativa institucional sin renunciar a la conceptualización y gestión compartida desde los vecinos. Se trata por tanto de nuevos espacios híbridos, a raíz de la diversidad de agentes que participan y por el significado social que así recibe la estética urbana.

Desde otra perspectiva, la diversidad tipológica de los espacios públicos abiertos permite analizar no solo elementos de la estructura y la morfología urbanas sino que también anima a reflexionar sobre el importante papel que estos representan para el conjunto de la sociedad. Carmen Rosa Delgado Acosta y Carmen Gloria Calero Martín escriben Los espacios públicos urbanos: lugares para el aprendizaje geográfico apoyándose en este argumento general y observando, especialmente, la oportunidad que ofrecen los espacios públicos abiertos como lugares de aprendizaje. Sin duda alguna, constituyen un excelente recurso educativo en donde alcanzar gran parte de los objetivos y las competencias que la Geografía tiene programadas en la Educación Secundaria Obligatoria y el Bachillerato.

Para terminar, como todos los números de la revista, el que sigue acaba en una sección de Lecturas, Eventos y Debates. Abre la misma una reflexión, tan personal en el formato como notable en el contenido, por parte de Jorge Benavides Solís. Bajo el título de Sin espacio públicos no hay ciudad se desarrolla un amplio y detallado recorrido por la evolución del sentido del espacio público como quintaesencia de la ciudad - especialmente centrado en la ciudad occidental-. Un equilibrio inestable en la medida que los contextos económicos y/o ideológicos en los que se enmarquen las realidades urbanas, en el presente y en el futuro, pueden llegar a desnaturalizar esta íntima relación.

La experiencia descrita en el texto A Pensar Tu Barrio, proceso participativo para recuperar el espacio público del Casco Norte de Sevilla, elaborado por Isabel Jiménez López y los representantes de la Asociación Vecinal "La Revuelta” (Manuel Calvo Salazar, Francisco Sánchez Díaz y Rafael 
Ibáñez Reche), antepone la visión participativa y la viabilidad de la intervención concreta sobre otras consideraciones. Está basada en un proceso diseñado de manera participada con el objetivo de modificar el sistema de movilidad del barrio, definiendo colectiva y pluralmente cómo debe replantearse el uso de las calles y del espacio público.

Termina el número con la reseña de Pascual Riesco "Una interpretación teórico-cultural de la ciudad de Sevilla. Reseña de Schwab (2013) Texturas de una ciudad". Una reseña reflexiva de una obra de amplia perspectiva cultural que huye de descripciones costumbristas y nos recuerda que el imaginario y los relatos de una ciudad, son, en sí mismos, un capital colectivo que, si bien tozudo, como los espacios urbanos se construye sobre la acumulación de sustratos sociales, históricos o económicos, entre otros.

GARCÍA GARCÍA, Antonio y José TORRES GUTIÉRREZ. Espacios públicos y construcción de ciudad. Hábitat y Sociedad, 2015, n. ${ }^{\circ}$, pp. 5-8.

$<$ www.habitatysociedad.us.es>

http://dx.doi.org/10.12795/HabitatySociedad.2016.i9.01 